ARTICLE

\title{
Both Boceprevir and GC376 efficaciously inhibit SARS-CoV-2 by targeting its main protease
}

Lifeng Fu (1) 1,2,9, Fei Ye ${ }^{3,9}$, Yong Feng ${ }^{1,4,9}$, Feng $\mathrm{Yu}^{5}$, Qisheng Wang ${ }^{5}$, Yan Wu ${ }^{6,7}$, Cheng Zhao ${ }^{1}$, Huan Sun ${ }^{1}$, Baoying Huang ${ }^{3}$, Peihua $\mathrm{Niu}^{3}$, Hao Song (1) ${ }^{6}$, Yi Shi (i] ${ }^{1,2,8}$, Xuebing Li (i] ${ }^{1,4 凶}$, Wenjie Tan (1) ${ }^{3 凶}$, Jianxun $\mathrm{Qi}^{1,8 凶} \&$ George Fu Gao (i) ${ }^{1 \times}$

COVID-19 was declared a pandemic on March 11 by WHO, due to its great threat to global

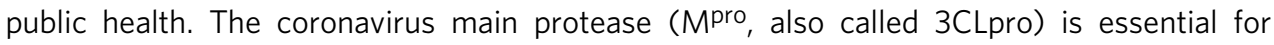
processing and maturation of the viral polyprotein, therefore recognized as an attractive drug target. Here we show that a clinically approved anti-HCV drug, Boceprevir, and a pre-clinical inhibitor against feline infectious peritonitis (corona) virus (FIPV), GC376, both efficaciously inhibit SARS-CoV-2 in Vero cells by targeting Mpro. Moreover, combined application of GC376 with Remdesivir, a nucleotide analogue that inhibits viral RNA dependent RNA polymerase (RdRp), results in sterilizing additive effect. Further structural analysis reveals binding of both inhibitors to the catalytically active side of SARS-CoV-2 protease Mpro as main mechanism of inhibition. Our findings may provide critical information for the optimization and design of more potent inhibitors against the emerging SARS-CoV-2 virus.

\footnotetext{
${ }^{1}$ CAS Key Laboratory of Pathogenic Microbiology and Immunology, Institute of Microbiology, Chinese Academy of Sciences, 100101 Beijing, China. ${ }^{2}$ Center for Influenza Research and Early Warning (CASCIRE), CAS-TWAS Center of Excellence for Emerging Infectious Disease (CEEID), Chinese Academy of Sciences, 100101 Beijing, China. ${ }^{3}$ NHC Key Laboratory of Biosafety, National Institute for Viral Disease Control \& Prevention, Chinese Center for Disease Control and Prevention, China CDC, 102206 Beijing, China. ${ }^{4}$ University of Chinese Academy of Sciences, 100049 Beijing, China. ${ }^{5}$ Shanghai Synchrotron Radiation Facility, Shanghai Advanced Research Institute, Chinese Academy of Sciences, 201204 Shanghai, China. ${ }^{6}$ Research Network of Immunity and Health (RNIH), Beijing Institutes of Life Science, Chinese Academy of Sciences, 100101 Beijing, China. ${ }^{7}$ Department of Pathogen Microbiology, School of Basic Medical Sciences, Capital Medical University, 100069 Beijing, China. ${ }^{8}$ Savaid Medical School, University of Chinese Academy of Sciences, 100049 Beijing, China. ${ }^{9}$ These authors

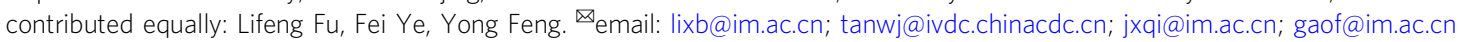


n December 2019, a novel coronavirus was discovered due to emerging viral pneumonia cases ${ }^{1-5}$. The virus has rapidly spread to more than 200 countries in the world ${ }^{6,7}$. The World Health Organization (WHO) named the infectious disease as COVID-19, and declared a global pandemic on 11 March $2020^{8}$. As of 28 March, the disease has caused more than 500,000 human infections with over 20,000 deaths globally 9 .

Human coronavirus $2019(\mathrm{HCoV}-19)^{10}$ is the seventh coronavirus capable of infecting humans, which was later named SARS-CoV-2 by the International Committee on Taxonomy of Viruses (ICTV) ${ }^{11}$ though with different name being proposed. The other six coronaviruses are the low-pathogenicity members including HCoV-OC43, HCoV-HKU1, HCoV-NL63, and HCoV229E, and highly pathogenic SARS-CoV and MERS-CoV ${ }^{12}$. The clinical manifestations of COVID-19 include fever, fatigue, dry cough, headache, and diarrhea ${ }^{13}$. The median incubation period of the disease is 4 days, and the longest is no more than 41 days ${ }^{13}$. The patient at incubation period is contagious, and the median duration of viral shedding was 20 days in survivors, but the SARS-CoV-2 was detectable until death in non-survivors ${ }^{14}$. The longest observed duration of viral shedding in survivors was 37 days $^{14}$. Some mildly ill patients do not have fever and obvious respiratory symptoms ${ }^{14}$. Most of the patients have a good prognosis, and the symptoms of children are relatively mild ${ }^{14}$. The patients with older age and comorbidities such as hypertension, diabetes, and coronary heart disease will have high risk of death ${ }^{14}$.

Sequence comparison has showed that the SARS-CoV-2 has the closest relationship $(96.2 \%)$ with the bat SARS-like coronavirus $^{4,12}$, but the origin of this virus was yet to be identified. Recent studies have shown that the SARS-CoV-2 uses the same Angiotensin-converting enzyme 2 (ACE2) receptor as SARS-CoV ${ }^{4}$, and the structural basis of receptor recognition was quickly elucidated to provide important basis for the molecular understanding of virus entry process and the development of potential antiviral inhibitors ${ }^{15-18}$. Some old drugs such as Remdesivir, Favipiravir, and Chloroquine/Hydroxychloroquine, and also traditional Chinese medicines showed potential for the treatment of COVID-1919-22. However, to date, no clinically approved specific drugs or vaccines are available to treat the disease. Therefore, it is urgent to develop specific drugs against the virus.

The coronavirus main protease (Mpro, 3CLpro) is essential for viral polyproteins processing and maturation, therefore, it is recognized as an attractive drug target. Actually, viral proteases are also promising targets for many different viruses including hepatitis $\mathrm{C}$ virus (HCV)and human immunodeficiency virus $(\mathrm{HIV})^{23}$. As there is neither specific antiviral agents nor available vaccines, repurposing of clinically approved drugs to combat the COVID-19 is urgently needed. Here we show both Boceprevir and GC376 can inhibit Mpro activity and SARS-CoV-2 in Vero cells. Moreover, combination of GC376 with Remdesivir treatment can enhance antiviral activity. Additionally, the highresolution crystal structures of SARS-CoV-2 Mpro complex with these two inhibitors are solved to figure out their mechanism of inhibition. Taken together, these data provide critical information for the optimization and design of more potent inhibitors against the emerging pathogen SARS-CoV-2.

\section{Results}

High throughput drug screening. In the beginning, we obtained soluble and pure Mpro protein of the SARS-CoV-2 with an extra glycine residue at the $\mathrm{N}$-terminus (GMPro) after TEV cleavage by expression in E. coli cells. At the same time, we found that the Mpro of SARS-CoV-2 has high homology with other CoV Mpro (Supplementary Fig. 1). So, we selected a cluster of 18 chemical

\begin{tabular}{|lll|}
\hline \multicolumn{2}{l}{ Table 1 Eighteen anti-proteinase compounds were selected } \\
for screening. & & \\
Number & Target & Drug name \\
\hline 1 & HIV Protease & Saquinavir \\
2 & HIV Protease & Ritonavir \\
3 & HIV Protease & Indinavir \\
4 & HIV Protease & Nelfinavir Mesylate \\
5 & HIV Protease & Amprenavir \\
6 & HIV Protease & Lopinavir \\
7 & HIV Protease & Atazanavir sulfate \\
8 & HIV Protease & Fosamprenavir \\
9 & HIV Protease & Tipranavir \\
10 & HIV Protease & Darunavir \\
11 & HCV NS3 protease & Boceprevir \\
12 & HCV NS3 protease & Telaprevir \\
13 & HCV NS3 protease & Simeprevir \\
14 & HCV NS3 protease & Asunaprevir \\
15 & HCV NS3 protease & Grazoprevir \\
16 & Proteasome & Carfilzomib \\
17 & Proteasome & Bortezomib \\
18 & 3C-Like Protease & GC376 sodium \\
\hline
\end{tabular}

drugs that were designed to target the different viral proteases and proteasome (Table 1). Then, we screened these chemical drugs by in vitro fluorescence resonance energy transfer (FRET) enzymatic assays at a single concentration $(100 \mu \mathrm{M}$; Fig. 1a, b). We identified two inhibitors, Boceprevir and GC376, can inhibit the enzymatic activity well (Fig. 1b). In contrast, other drugs such as Aluvia ${ }^{\circledast}$ (HIV protease inhibitors, lopinavir, and ritonavir) did not show detectable inhibitory activity, which is consistent with the reports of recent clinical trials that Aluvia ${ }^{\circledR}$ has no obvious effect on the treatment of COVID-1924.

Enzyme activity study and its structural basis. Before further evaluating protein level inhibitory activity of Boceprevir and GC376, we found that extra residues at the N-terminus would impair the enzyme activity in previous report ${ }^{25}$. Therefore, we expressed the native Mpro without any extra amino acids at the N-terminus (a gift from Dr Haitao Yang in ShaghaiTech University) according to the literature ${ }^{26}$. Then, we compared GMpro activity with the native Mpro. Substrate hydrolysis rate of the native Mpro (frist $1000 \mathrm{~s}$ initial speed $v_{0}=1618 \pm 84 \mathrm{RFU} \mathrm{s}^{-1}$ ) is almost three times faster than that of GMpro (first $1000 \mathrm{~s}$ initial speed $v_{0}=449 \pm 19 \mathrm{RFU} \mathrm{s}^{-1}$ ), which must be caused by extra Gly at the $\mathrm{N}$ terminus (Supplementary Fig. 2a). Again, our data readdress the importance of the free $\mathrm{N}$-terminus after previous report of 2 or 5 extra amino acids, showing 20 -fold or 150 -fold slower catalytic efficiency ${ }^{25}$. In order to figure out how the glycine at the N-terminus affects protease activity, we crystallized the GMpro protein and solved the crystal structure at a resolution of 2.0 $\AA$. The overall structure of GMpro is highly similar to those of SARS-CoV-2 native Mpro and SARS-CoV native Mpro (Supplementary Fig. 3a). The first residue Ser is disordered in GMpro structure, indicating this residue cannot stabilize Glu166 of the S1 subsite in the neighboring protomer, which may be the main reason for the decrease of enzyme activity (Supplementary Fig. 3a). However, the extra glycine did not induce the main chain of residues 141-142 moves towards the S1 subsite as seen in previous report with five extra amino acids ${ }^{25}$ (Supplementary Fig. 3b).

Enzyme inhibitory activity of Boceprevir and GC376. Boceprevir is a serine protease inhibitor that was approved by FDA to treat $\mathrm{HCV}$ infection in 2011. It was reported that the ketoamide 

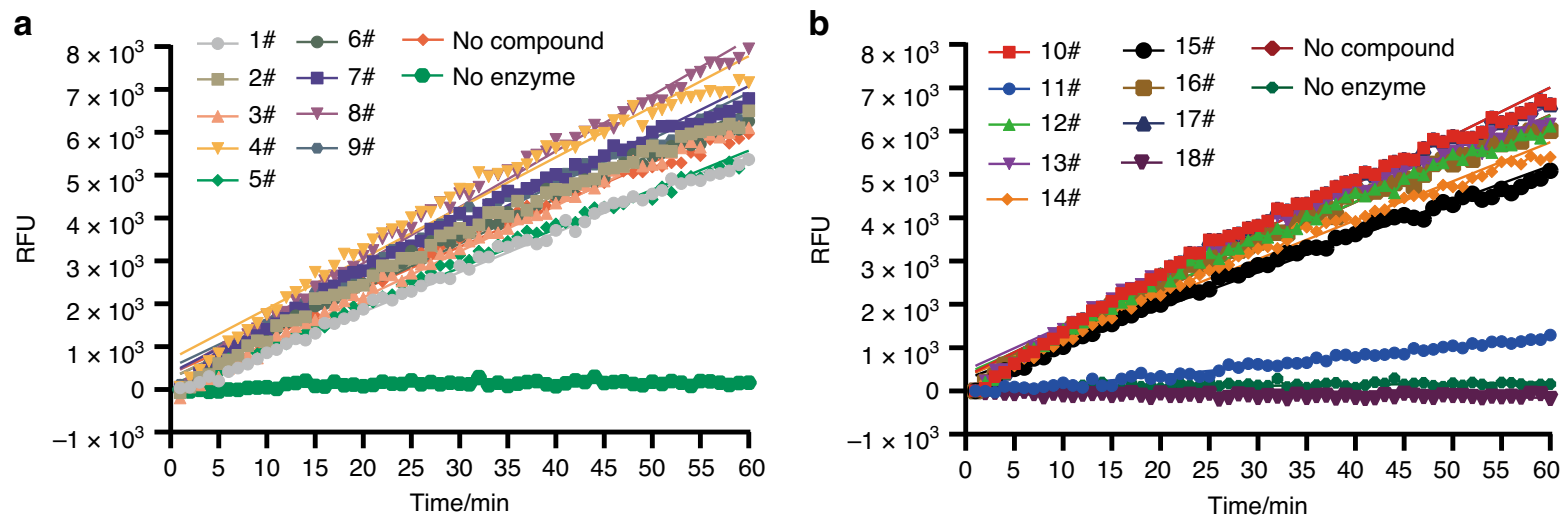

C

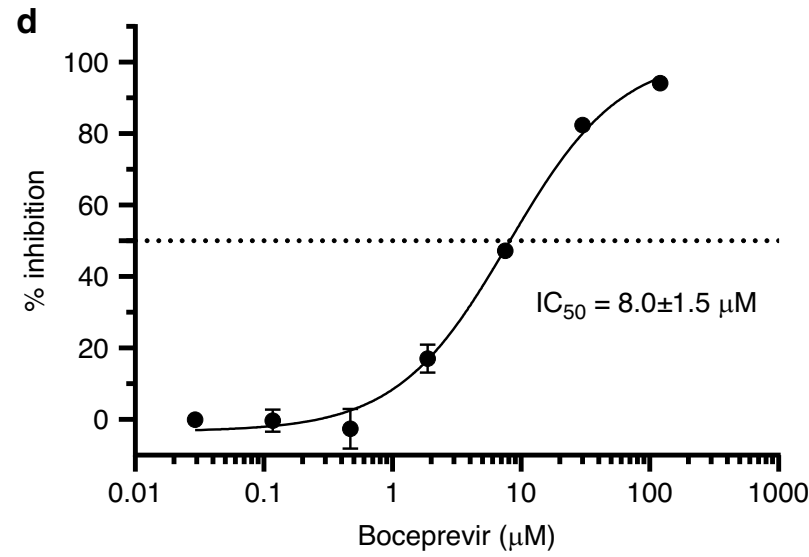

e

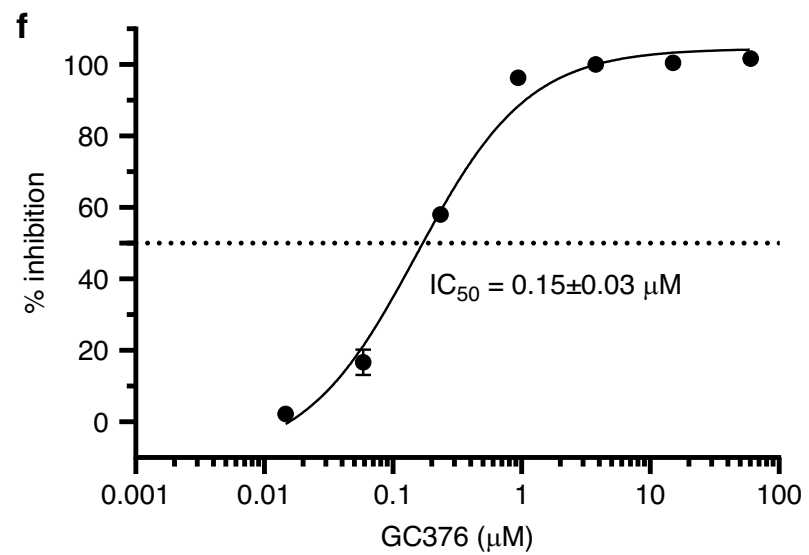

Fig. 1 Boceprevir and GC376 can inhibit the catalytic activity of SARS-CoV-2 $\mathbf{M}^{\text {pro }}$ in vitro. $\mathbf{a}$, $\mathbf{b}$ The initial screening assay for these compounds. Chemical structure of Boceprevir (c) and GC376 (e). d, f The inhibitory assay of Boceprevir (d) and GC376 (f) show efficient inhibition for Mpro. Error bars: mean \pm S.D. of three independent replicates. Source data are provided as a source data file.

group of Boceprevir can reversibly bind covalently to the Ser139 of HCV NS3/4A protease, whose hydroxyl group function as nucleophilic groups in enzymatic reaction ${ }^{27}$. Boceprevir was shown to be a time-dependent inhibitor with a fast-initial binding followed by a slow formation of the covalent adduct against NS3/ $4 \mathrm{~A}$ protease $^{28}$. GC376 is a cysteine protease covalent inhibitor against picornaviruses, noroviruses, and coronaviruses, and has shown promise in treating cats with fatal feline infectious peritonitis (FIP) caused by FIPV ${ }^{29,30}$. For time-dependent inhibitors, we tried to evaluate the equilibrium-binding constant $K_{\mathrm{i}}$ and the inactivation rate constant $k_{\text {inac }}$ for covalent bond formation of Boceprevir and GC376 without preincubation. Progress curve of peptide hydrolysis by Mpro showed the inactivation processes of both two inhibitors are very slow (Supplementary Fig. 2b, c). So we used the $\mathrm{IC}_{50}$ values of these two inhibitors, $8.0 \mu \mathrm{M}$ and 0.15 $\mu \mathrm{M}$, to represent the inhibitory activity (Fig. 1d, f), which has also been used in other covalent inhibitor studys ${ }^{31,32}$. Meanwhile, we have performed the inhibition assay to test if these two compounds inhibit bovine chymotrypsin at the concentrations of 20 and $50 \mu \mathrm{M}$ (Supplementary Fig. 2d). The results showed that GC376 does not have any inhibition activity against the bovine chymotrypsin, while Boceprevir shows very trivial inhibition activity, indicating the Mpro inhibitory activity of these two compounds are specific.

Antiviral results of Boceprevir and GC376. We further evaluated the inhibition effects of the two inhibitors on the replication of live virus. Both Boceprevir and GC376 showed effects against the SARS-CoV-2, with $\mathrm{EC}_{50}$ values of $15.57 \mu \mathrm{M}$ and 
a

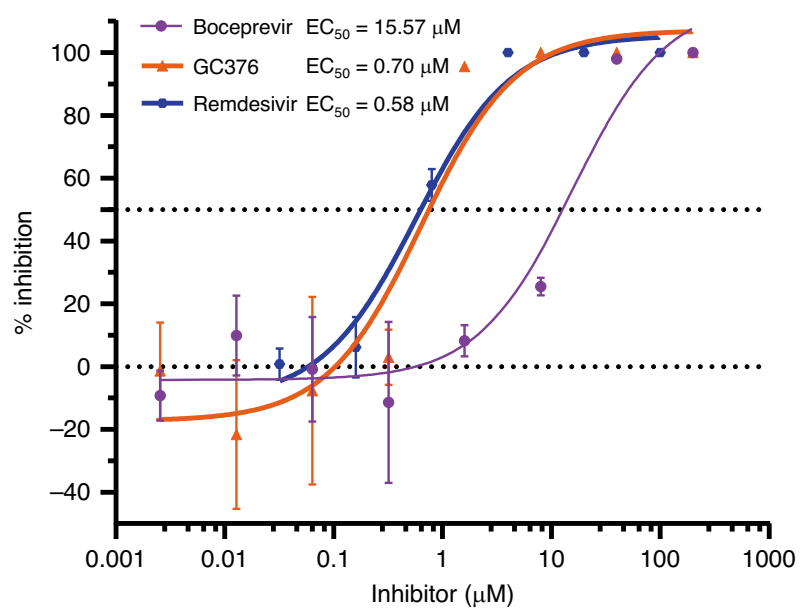

C

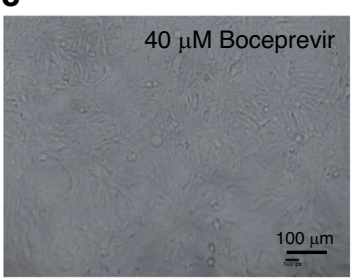

d

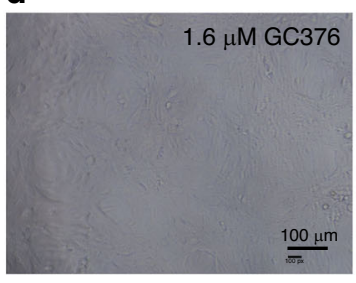

b

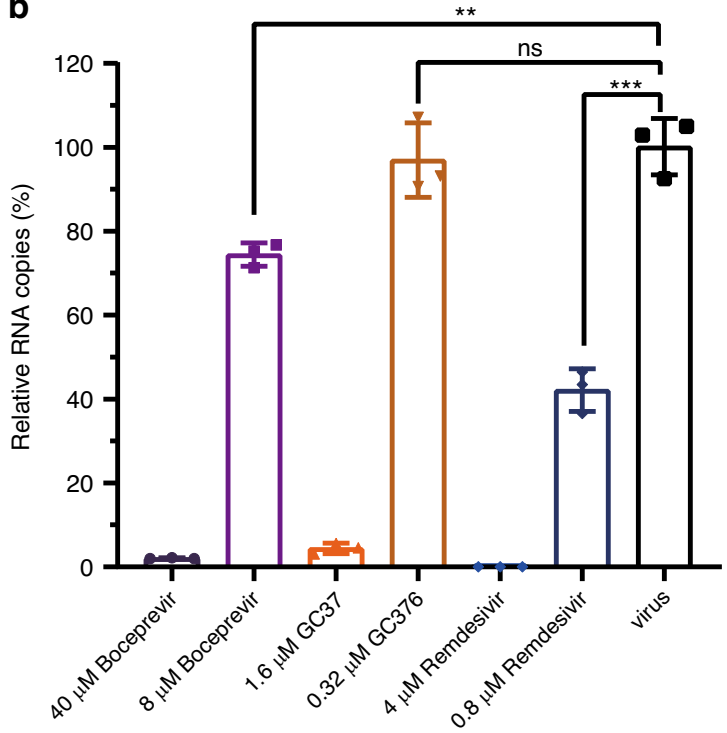

e

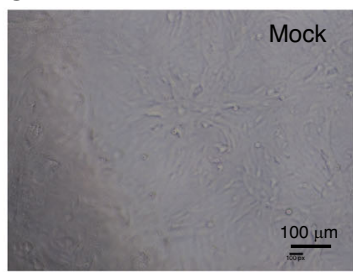

$\mathbf{f}$

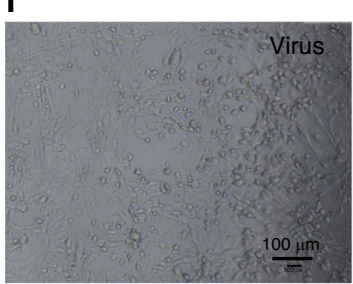

Fig. 2 Inhibition of SARS-CoV-2 replication in Vero cells by Boceprevir and GC376. a The inhibitory effect of Boceprevir and GC376 treatment on SARSCoV-2 replication. Remdesivir was used as a positive control. $\mathbf{b}$ The relative concentration of viral RNA present in the supernatant at $72 \mathrm{~h}$ post infection determined by Real-time quantitative PCR analysis after Boceprevir and GC376 treatment, unpaired $t$ test for comparison of relative viral RNA copies incubated with inhibitor vs virus control ( $n=3$ independent replicates). $p=0.0036,0.6474,0.0003$ for $8 \mu \mathrm{M}$ Boceprevir, $0.32 \mu \mathrm{M}$ GC376, and $0.8 \mu \mathrm{M}$ Remdesivir, respectively (ns: not significant $P>0.05,{ }^{\star \star} P<0.01,{ }^{\star \star \star} P<0.001$ ). c-f Virus-induced cytopathic effect in Vero cells after Boceprevir and GC376 treatment. Scale bar represents $100 \mu \mathrm{m}$. Error bars: mean \pm S.D. of three independent replicates. Source data are provided as a source data file.

$0.70 \mu \mathrm{M}$, respectively (Fig. 2a). As a positive control, Remdesivir inhibited the SARS-CoV-2 replication with an $\mathrm{EC}_{50}$ value of $0.58 \mu \mathrm{M}$. No obvious pathological changes were observed when cells were incubated with $40 \mu \mathrm{M}$ Boceprevir (Figs. 2c) or $1.6 \mu \mathrm{M}$ GC376 (Fig. 2d) after infection. These compounds did not show obvious cytotoxicity at a concentration up to $200 \mu \mathrm{M}$ in Vero cells (Supplementary Fig. 4). In order to further validate the antiviral effect of these inhibitors, we performed the traditional plaque assay stained with crystal violet. The plaque produced by the SARS-CoV-2 does not look like circles, which caused that it is difficult to quantify the antiviral efficacy for GC376 and Boceprevir. The possible reason is that the virus has been incubated with cells for a long time and multiple plaques are connected together. However, in presence of $40 \mu \mathrm{M}$ Boceprevir or $1.6 \mu \mathrm{M}$ GC376, the size and number of plaques are obviously smaller and less (Supplementary Fig. 5a, b). In addition, combination of $1 \mu \mathrm{M}$ GC376 and $1 \mu \mathrm{M}$ Remdesivir can completely inhibit viral replication in virus plaque assay (Supplementary Fig. 5d), showing additive effect of the joint application of RdRp inhibitors and protease inhibitors targeting different viral proteins.

Inhibition mechanism of Boceprevir and GC376 against Mpro. In order to elucidate the inhibitory mechanisms of these two compounds, we determined the crystal structures of Mpro-Boceprevir and Mpro_GC376 complexes at resolutions of $1.60 \AA$ and $2.00 \AA$, respectively (Supplementary Fig. 6 and Supplementary Table 1). The unambiguous electron density maps show that the two inhibitors bind in the active site of Mpro in different conformations (Supplementary Fig. 7). In the Mpro-Boceprevir complex structure, the $\mathrm{S} \gamma$ atom of the nucleophilic Cys145 in Mpro forms a C-S covalent bond with the keto carbon of Boceprevir, which is a typical Michael addition (Fig. 3a, b and Supplementary Fig. 8a). Residues His41, Gly143, and His164 form four hydrogen-bonding interactions with the amide backbone of Boceprevir in one side, and residue Glu166 form three hydrogenbonding interactions with Boceprevir in the other side. The small size of cyclobutylalanice (c-Bua) residue can be tolerated by $\mathrm{S} 1$ subsite. However, the P1 c-Bua residue has no interaction with S1 subsite (Fig. 3b). The hydrophilic Glu166 pushes the P1 hydrophobic group away and exposes the c-Bua residue to solvent. This can explain why Boceprevir displays a moderate activity against Mpro. The rigid P2 dimethylcyclopropylproline (DMCP) residue can fit S2 subsite well (Fig. 3a) and has hydrophobic interaction with Met149 and Asp187 (Supplementary Fig. 8a). The hydrophobic $\mathrm{P} 3$ and $\mathrm{P} 4$ tert-butyl $(\mathrm{tBu})$ residue can interact with Met165 in S3 subsite and Gln189, Gln192, Thr190 in S4 subsite (Supplementary Fig. 8a). Compared with HCV NS3/ $4 \mathrm{~A}$-Boceprevir complex ${ }^{27}$, the binding pocket are quite different due to low structural similarity, and the compound has large conformational changes to fit the HCV NS3/4A binding pocket (Fig. 3c). In all, 80\% P1 c-Bua residue of Boceprevir is buried in S1 subsite which contributes the largest factor to binding. By contrast, in the SARS-CoV-2 Mpro-Boceprevir complex structure, the P2 DMCP residue and P4 tBu cap are $80 \%$ buried other than P1 c-Bua residue. About $40 \%$ of $\mathrm{P} 2, \mathrm{P} 3$, and $\mathrm{P} 4$ residues are 
a

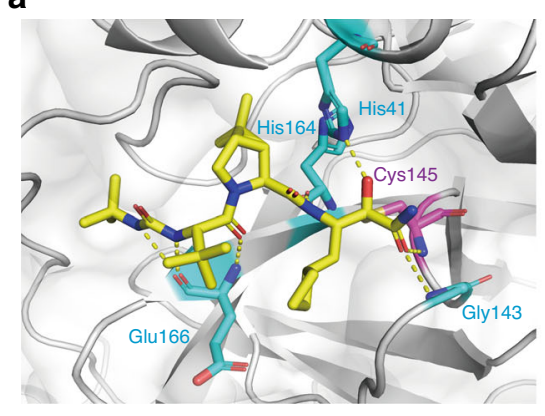

d

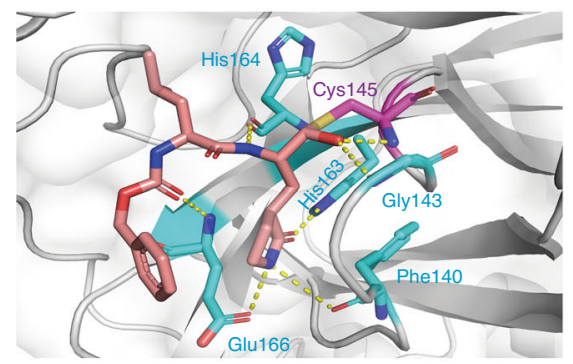

b

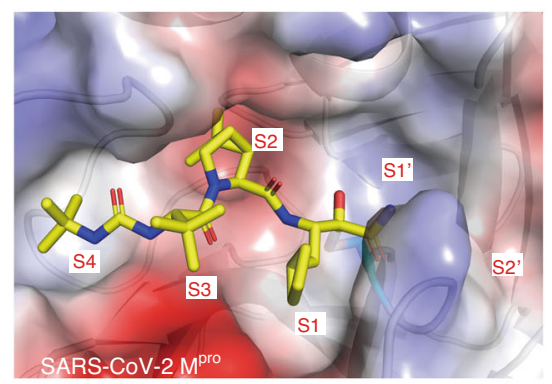

e

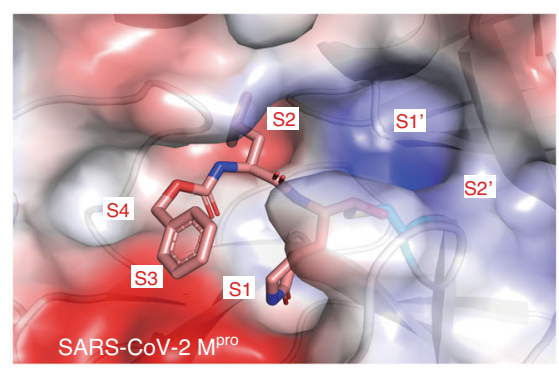

C

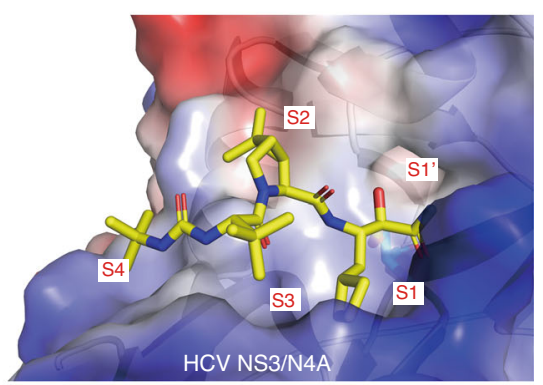

f

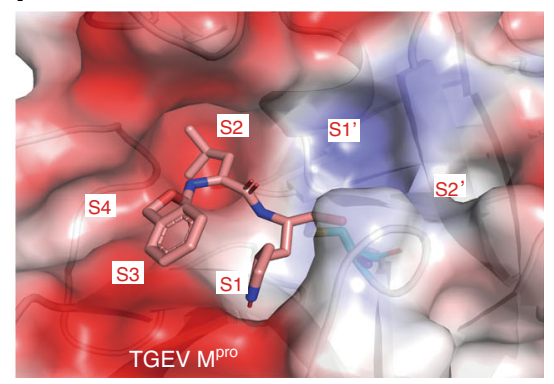

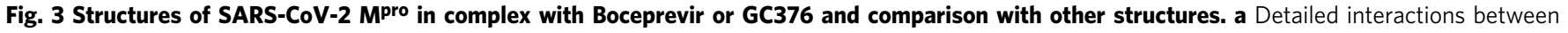

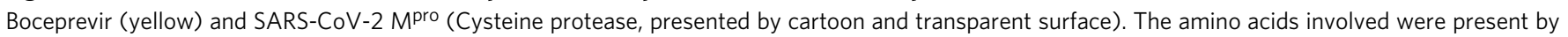

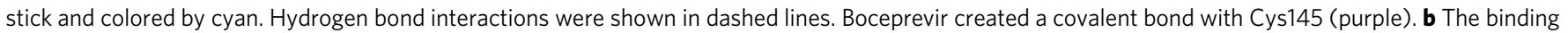

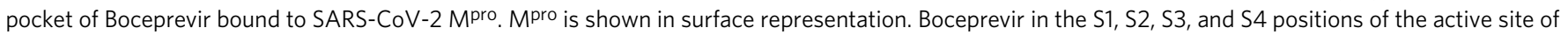
SARS-CoV-2 Mpro were labeled. c The binding pocket of Boceprevir bound to hepatitis C virus (HCV) NS3/4A serine protease (PDB: 2OC8). The S1, S2, S3, and S4 positions of the active site of HCV NS3/4A serine protease were labeled. Boceprevir created a covalent bond with Ser139. d Detailed interactions between GC376 (pink) and SARS-CoV-2 Mpro. GC376 created a covalent bond with Cys145 (presented by stick and colored by purple). e The binding pocket of GC376 bound to SARS-CoV-2 Mpro. GC376 in the S1, S2, and S3 positions of the active site of SARS-CoV-2 Mpro were labeled. $\mathbf{f}$ The binding pocket of GC376 bound to Transmissible gastroenteritis coronavirus (TGEV) MPro (PDB: 4F49). GC376 in the S1, S2, and S3 positions of the active site of TGEV Mpro (present by charged surface) were labeled, and GC376 created a covalent bond with Cys144.

buried in S2, S3, and S4 subsite of $\mathrm{HCV} \mathrm{NS3/4A} \mathrm{protease,} \mathrm{which}$ are highly exposed to solvent (Fig. 3c) ${ }^{27}$.

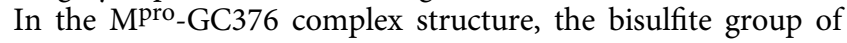
GC376 was removed and GC376 created a covalent bond with Cys145 as aldehyde form in the complex structure (Fig. 3d, e and Supplementary Fig. 8b). The glutamine surrogate ring of GC376 fits into the S1 pocket and has hydrogen bonding interactions with the carboxyl group of Glu166. The Leu of GC376 fits into S2 hydrophobic pocket, which is consists of residues Arg40, His41, Met49, Tyr54, and Asp187. Compared with transmissible gastroenteritis virus (TGEV) Mpro_ GC376 complex, both the binding pocket and the configuration of GC376 are highly similar, suggesting a conserved interaction mode for GC376 against different coronaviruses (Fig. 3f). The crystal structures of GMPro-Boceprevir and GMPro_GC376 complexes at resolutions of $1.80 \AA$ and $1.40 \AA$ was also determined to evaluate the influences of the extra glycine at $\mathrm{N}$ terminal. Compared to Mpro-Boceprevir, only P4 residue of Boceprevir has slight changes in GMPro_ Boceprevir complex (Supplementary Fig. 3c). The binding mode of GC376 with GMpro or Mpro has no obvious changes (Supplementary Fig. 3d).

\section{Discussion}

We have performed the SAR analysis of other 3CLpro inhibitors reported recently. Compared with the inhibitors N3 ${ }^{26}, 13 \mathrm{a}$ $\left(\mathrm{IC}_{50}=0.67 \mu \mathrm{M}\right)^{31}, 11 \mathrm{a}\left(\mathrm{IC}_{50}=0.053 \mu \mathrm{M}\right)$, and $11 \mathrm{~b}\left(\mathrm{IC}_{50}=\right.$ $0.04 \mu \mathrm{M})^{32}$, the P1 c-Bua residue is very important for inhibition activity. P2 moieties bulkier than cyclohexane of $13 \mathrm{~b}$ and cyclopropane of 11a may be tolerant, which has been proved in the Mpro-Boceprevir complex structure. Introduction of hydrogen bond acceptor $\mathrm{F}$ at $\mathrm{P} 2$ residue in $11 \mathrm{~b}$ which has hydrogen bond interaction with Q189 can increase inhibition activity. The indole group of $11 \mathrm{a} / 11 \mathrm{~b}$ and the benzene ring group of GC376 showed that P3 is more suitable for aromatic conjugated group.

During our initial screen, there are four other HCV protease inhibitors which showed much lower activity against the main protease of SARS-CoV-2. Telaprevir, also a covalent inhibitor of serine protease ${ }^{33}$, loses inhibition activity against Mpro of SARS$\mathrm{CoV}-2$ which may be caused by steric hindrance of the large P2 quinoxaline moiety. The active pocket of HCV serine protease is larger and more solvent exposed than that of SARS-CoV-2 Mpro according to the complex structures of HCV serine protease cocrystallization with the inhibitors simeprevir, asunaprevir, and grazoprevir ${ }^{34-36}$. Therefore, the macrocyclic compound simeprevir, asunaprevir, and grazoprevir can not be accommodated in the relatively narrower pocket of SARS-CoV-2 Mpro.

As we presented in the text, GC376 has more potent inhibition efficiency than Boceprevir, which makes GC376 might be more advantageous than Boceprevir in the clinical practice. However, GC376 has shown side effects such as retarded development of adult teeth in the animal tests ${ }^{37}$. The delayed eruption of some adult teeth was observed only in cats treated for 3 months or longer, not in cats treated for 2 weeks ${ }^{38}$. Therefore, GC376 has the potential to be a short-term treatment of COVID-19 for 1-2 weeks in combination with Remdesivir, because of COVID19 is an acute disease.

In a word, the structural basis of interaction between the compounds and the main protease provides a good starting point 
for the optimization and design of more potent drugs against the COVID-19.

\begin{abstract}
Methods
Protein expression and purification. To express the SARS-CoV-2 Mpro protein with an extra glycine residue at the $\mathrm{N}$-terminus, the cDNA encoding residues 3264-3569 of ORF1ab (GenBank: MN908947.3) was synthesized and codonoptimized for expression in E. coli. The coding sequence was then cloned into the NcoI and NotI sites of the pET-52b vector (Genscript) with a N-terminal tag followed by TEV cleavage sequences. The recombinant protein was expressed in $E$. coli strain BL21 (DE3) as soluble proteins after inducing with $0.2 \mathrm{mM}$ isopropyl- $\beta$ d-thiogalactopyranoside (IPTG) at an $\mathrm{OD}_{600}$ of $0.6-0.8$ and expressing at $16^{\circ} \mathrm{C}$ for $18 \mathrm{~h}$. The cells were lysed by sonication in the lysis buffer $(20 \mathrm{mM}$ Tris, $50 \mathrm{mM}$ $\mathrm{NaCl}, 20 \mathrm{mM}$ imidazole, $\mathrm{pH} 8.0$ ). After $19,802 \times g$ centrifugation $30 \mathrm{~min}$, the supernatants were then purified by affinity chromatography using the HisTrap HP $5 \mathrm{ml}$ columns (GE Healthcare). The target protein was eluted with the elution buffer $(20 \mathrm{mM}$ Tris, $50 \mathrm{mM} \mathrm{NaCl}, 300 \mathrm{mM}$ imidazole, $\mathrm{pH} 8.0)$. The purified proteins per mg were incubation with $2 \mu \mathrm{L}$ reconstruction TEV protease (Solarbio, $\mathrm{P} 2060)$ at $30^{\circ} \mathrm{C}$ for $2 \mathrm{~h}$ after centrifugation. The hydrolyzed proteins were then purified by affinity chromatography using the HisTrap HP $5 \mathrm{ml}$ columns (GE Healthcare) again and further purified by size-exclusion chromatography using a Hiload 16/600 Superdex 75 PG column (GE Healthcare) equilibrated with the binding buffer ( $20 \mathrm{mM}$ Tris- $\mathrm{HCl}, 150 \mathrm{mM} \mathrm{NaCl}, 1 \mathrm{mM}$ DTT, $1 \mathrm{mM}$ EDTA, and $\mathrm{pH}$ 7.8). Expression and purification of the native SARS-CoV-2 Mpro protein were performed according to literature ${ }^{26}$. The recombinant protein was expressed in $E$. coli strain BL21 (DE3) as soluble proteins after inducing with $0.5 \mathrm{mM}$ IPTG at an OD600 of $0.6-0.8$ and expressing at $16^{\circ} \mathrm{C}$ overnight. The cells were lysed by sonication in the lysis buffer $(20 \mathrm{mM}$ Tris, $50 \mathrm{mM} \mathrm{NaCl}$, pH 8.0). After 19,802 $\times g$ centrifugation $30 \mathrm{~min}$, the supernatants were then purified by affinity chromatography using the HisTrap HP $5 \mathrm{ml}$ columns (GE Healthcare). The target protein was eluted with the elution buffer $(20 \mathrm{mM}$ Tris, $50 \mathrm{mM} \mathrm{NaCl}, 300 \mathrm{mM}$ imidazole, and $\mathrm{pH}$ 8.0). The purified proteins per mg were incubation with $20 \mu \mathrm{L}$ recombinant human rhinovirus protease (Genscript, Z03092) at $30^{\circ} \mathrm{C}$ for $2 \mathrm{~h}$ after centrifugation. The hydrolyzed proteins were then purified by affinity chromatography using the HisTrap HP $5 \mathrm{ml}$ columns (GE Healthcare) again and further purified by sizeexclusion chromatography using a Hiload 16/600 Superdex 75 PG column (GE Healthcare) equilibrated with the binding buffer $(20 \mathrm{mM}$ Tris- $\mathrm{HCl}, 150 \mathrm{mM} \mathrm{NaCl}$, 1 mM DTT, 1 mM EDTA, pH 7.8).
\end{abstract}

Antiviral compounds. Saquinavir (Cat no. HY-17007), Ritonavir (Cat no. HY90001), Indinavir (Cat no. HY-B0689), Nelfinavir Mesylate (Cat no. HY-15287A), Amprenavir (Cat no. HY-17430), Lopinavir (Cat no. HY-14588), Atazanavir sulfate (Cat no. HY-17367A), Fosamprenavir (Cat no. HY-78726), Tipranavir (Cat no. HY-15148), Darunavir (Cat no. HY-17040), Boceprevir (Cat no. HY-10237), Telaprevir (Cat no. HY-10235), Simeprevir (Cat no. HY-10241), Asunaprevir (Cat no. HY-14434), Grazoprevir (Cat no. HY-15298), Carfilzomib (Cat no. HY-10455), and Bortezomib (Cat no. HY-10227) were purchased from MedChemExpress. GC376 (Cat no. T5188) were purchased from TargetMol.

Enzyme activity study. In all, $10 \mu \mathrm{L}$ of $100 \mu \mathrm{M}$ substrate solution (DabcylTSAVLQ \SGFRKMK-Edans) (Genscript) was added to black 96-well plate (Greiner) with $40 \mu \mathrm{L}$ final concentration of $200 \mathrm{nM}$ GMpro or native Mpro in 25 $\mathrm{mM}$ Tris buffer $(\mathrm{pH}=8.0)$. The relative fluorescence units $(\mathrm{RFU})$ value was measured with an excitation wavelength of $360 \mathrm{~nm}$ and emission wavelength of $490 \mathrm{~nm}$ at $37^{\circ} \mathrm{C}$ for $1 \mathrm{~h}$ by using SpectraMax Paradigm Muti-Mode Detection Platform (Molecular Devices, USA) ${ }^{31}$. Experiments were performed in triplicate. Then the progress curve of peptide hydrolysis was plotted by GraphPad Prism 8.0. First $1000 \mathrm{~s}$ change of fluorescence value was used to calculate the initial rate $v_{0}$ by SoftMax Pro 7.1.

$\mathbf{M}^{\text {pro }}$ enzyme activity inhibition test. Compounds in Table 1 were diluted in 25 $\mathrm{mM}$ Tris buffer $(\mathrm{pH}=8.0)$ to a final concentration of $100 \mu \mathrm{M}$ for screen. DMSO was used as a solvent control. In all, $10 \mu \mathrm{L}$ compound solution was add to black 96well plate (Greiner). In total, $30 \mu \mathrm{L}$ of $2 \mu \mathrm{M} \mathrm{GM}^{\text {pro }}$ was added to the plate and incubated with the compounds at $37^{\circ} \mathrm{C}$ incubator for $30 \mathrm{~min}$. In total, $330 \mu \mathrm{L}$ of 25 $\mathrm{mM}$ Tris buffer was also added as blank control. Then $10 \mu \mathrm{L}$ of $20 \mu \mathrm{M}$ peptide substrate (Dabcyl-TSAVLQ $\downarrow$ SGFRKMK-Edans) solution (Genscript) in DMSO was added. The RFU value was measured with an excitation wavelength of $340 \mathrm{~nm}$ and emission wavelength of $490 \mathrm{~nm}$ at $37^{\circ} \mathrm{C}$ for $1 \mathrm{~h}$ by using a microplate reader (TECAN Infinite 200 Pro, Switzerland). The RFU change curves vs time with or without inhibitors were plotted by GraphPad Prism 8.0.

Because GC376 and Boceprevir are time-dependent covalent inhibitors, we evaluated the enzyme inhibitory activity without any preincubation. In all, $20 \mathrm{mM}$ GC376 and Boceprevir in DMSO were diluted to $60 \mu \mathrm{M}$ to $0.015 \mu \mathrm{M}$ and $120 \mu \mathrm{M}$ to $0.03 \mu \mathrm{M}$ by $25 \mathrm{mM}$ Tris buffer $(\mathrm{pH}=8.0)$ respectively. In total, $30 \mu \mathrm{L}$ inhibitor solution with a series of concentration in $25 \mathrm{mM}$ Tris buffer $(\mathrm{pH}=8.0)$ was mixed with $10 \mu \mathrm{L}$ of $100 \mu \mathrm{M}$ peptide substrate firstly. In total, $30 \mu \mathrm{L}$ Tris buffer was also mixed with $10 \mu \mathrm{L}$ of $100 \mu \mathrm{M}$ peptide substrate as negative control. Then, $10 \mu \mathrm{L}$ of $200 \mathrm{nM}$ final concentration of $\mathrm{M}^{\text {pro }}$ was added to the plate. The RFU value was measured with an excitation wavelength of $360 \mathrm{~nm}$ and emission wavelength of $490 \mathrm{~nm}$ at $37^{\circ} \mathrm{C}$ for $1 \mathrm{~h}$ by using SpectraMax Paradigm Muti-Mode Detection Platform (Molecular Devices, USA) ${ }^{39}$. Experiments were performed in triplicate. First $1200 \mathrm{~s}$ change of fluorescence value was used to calculate the reaction rate $v_{0}$ by SoftMax Pro 7.1. The reaction rate of different inhibitor concentration is divided by the reaction rate of the negative control to calculate the inhibition rate with Microsoft Excel 2016. Inhibition curve was plotted by GraphPad Prism 8.0.

Chymotrypsin enzyme activity inhibition test. In total, $10 \mu \mathrm{L}$ final concentration of $50 \mu \mathrm{M}, 20 \mu \mathrm{M}$ of GC376, and Boceprevir in $25 \mathrm{mM}$ Tris buffer $(\mathrm{pH}=8.0)$ was mixed with $10 \mu \mathrm{L}$ of $100 \mu \mathrm{M}$ peptide substrate (Dabcyl-KATVRLQAGNATEEEdans) solution (Genscript) in a black 96-well plate (Greiner). In all, $30 \mu \mathrm{L}$ of $1 \mu \mathrm{M}$ a-Chymotrypsin from bovine pancreas (Solarbio, C8660) in $25 \mathrm{mM}$ Tris buffer $(\mathrm{pH}=8.0)$ was then add to the plate. The RFU value was measured with an excitation wavelength of $360 \mathrm{~nm}$ and emission wavelength of $490 \mathrm{~nm}$ at $37^{\circ} \mathrm{C}$ for 1 h by using SpectraMax Paradigm Muti-Mode Detection Platform (Molecular Devices, USA). Experiments were performed in triplicate. The progress curve of peptide hydrolysis was plotted by GraphPad Prism 8.0.

Crystallization. In all, $8 \mathrm{mg} / \mathrm{ml}$ and $12 \mathrm{mg} / \mathrm{ml} \mathrm{GM}^{\text {pro }}$ or Mpro (in $10 \mathrm{mM}$ Tris, $1 \mathrm{mM}$ EDTA, $1 \mathrm{mM}$ DTT, pH 7.8) was incubated with $2 \mathrm{mM}$ inhibitor at $4{ }^{\circ} \mathrm{C}$ for $18 \mathrm{~h}$. All the crystals were obtained by using the sitting drop vapor diffusion method with $1 \mu \mathrm{L}$ protein mixing with $1 \mu \mathrm{L}$ reservoir solution and then equilibrating against $100 \mu \mathrm{L}$ reservoir solution at $18^{\circ} \mathrm{C}$. The initial crystallization screenings were carried out using the commercially available kits. The native GMPro was crystallized in 7\% PEG6000, $100 \mathrm{mM}$ MES (pH 6.1) ${ }^{40}$. The MPro Boceprevir and GMPro-Boceprevir were crystallized in 20\% PEG5000, $0.1 \mathrm{M}$ BISTRIS (pH 6.5). While the Mpro-GC376 and GMPro-GC376 complexes were crystallized in 14\% PEG4000, 0.1 M MES monohydrate ( $\mathrm{pH} 6.0$ ) and 10\% PEG6000, $0.1 \mathrm{M}$ MES (pH 6.1), and 3\% DMSO respectively.

Data collection and structure determination. Diffraction data were collected at Shanghai Synchrotron Radiation Facility (SSRF) BL17U (wavelength, $0.97918 \AA$ ). For data collection, the crystals were cryo-protected by briefly soaking in reservoir solution supplemented with $20 \%(\mathrm{v} / \mathrm{v})$ glycerol before flash-cooling in liquid nitrogen. The dataset was processed with HKL2000 software ${ }^{41}$. The native Mpro structure was determined by the molecular replacement method using Phaser ${ }^{42}$ with the previously reported SARS-CoV Mpro structure (PDB code, 3F9F), while the complexes were further determined with the solved $\mathrm{M}^{\mathrm{pro}}$ structure. The atomic models were completed with $\operatorname{Coot}^{43}$ and refined with phenix.refine in Phenix ${ }^{44}$, and the stereochemical qualities of the final models were assessed with MolProbity ${ }^{45}$. Data collection, processing, and refinement statistics are summarized in Supplementary Table 1. All structural figures were generated using Pymol software (http://www.pymol.org).

Cells and viruses. African green monkey kidney Vero cells were maintained in DMEM (Gibco, C11995500BT) supplemented with 10\% fetal bovine sera (FBS) (Gibco, A31608-02), $200 \mathrm{mg} / \mathrm{ml}$ streptomycin, and $200 \mathrm{IU} / \mathrm{ml}$ penicillin (Gibco, 15140122 ) at $37^{\circ} \mathrm{C}$. SARS-CoV-2 was isolated from Wuhan seafood market by China CDC. All the infection experiments were performed in a biosafety level-3 (BLS-3) laboratory.

Cell viability assay. The Vero cells were seeded in 96-well plate and cultured overnight. In total, $100 \mu \mathrm{L}$ different concentration of compound solution in DMEM was added to the Vero cells after PBS (Gibco, C10010500BT) wash and incubated for $48 \mathrm{~h}$ at $37^{\circ} \mathrm{C}, 5 \% \mathrm{CO}_{2}$. Meanwhile, $100 \mu \mathrm{L}$ DMEM was added to the Vero cells as negative control. In total, $10 \mu \mathrm{L}$ CCK8 assays (TargetMol, C0005) was added to each well directly. $\mathrm{OD}_{450}$ was measured by using a microplate reader (TECAN Infinite 200 Pro, Switzerland) after $3 \mathrm{~h}$ incubation at $37^{\circ} \mathrm{C}$. Experiments were performed in triplicate. $\mathrm{OD}_{450}$ value in present of different concentration of compound is divided by the $\mathrm{OD}_{450}$ value of the negative control to calculate the percentage cytotoxicity with Microsoft Excel 2016. The cytotoxicity curve was plotted by GraphPad Prism 8.0.

In vitro antiviral assays. In all, $20 \mathrm{mM} \mathrm{GC} 376$ and Boceprevir in DMSO were diluted to $200 \mu \mathrm{M}$ to $0.00256 \mu \mathrm{M}$ by DMEM contained 1\% FBS. In total, $10 \mathrm{mM}$ remdesivir in DMSO were diluted to $100 \mu \mathrm{M}$ to $0.032 \mu \mathrm{M}$. DMSO medium (1\%) was used as negative control. Vero cells cultured overnight in 96-well plate, were infected by $0.01 \mathrm{MOI}$ virus for $2 \mathrm{~h}$. The medium was removed, and fresh inhibitorcontaining medium was added to the cells then. Experiments were performed in quadruplicate. After $48 \mathrm{~h}$, the cell in triplicate was lysed in lysis buffer. Viral RNA was extracted from $100 \mu \mathrm{L}$ supernatant of infected cells using the automated nucleic acid extraction system (TIANLONG, China), following the manufacturer's recommendations. SARS-CoV-2 detection was performed using the One Step PrimeScript RT-PCR kit (TaKaRa, Japan) on the LightCycler ${ }^{\circledR} 480$ Real-Time PCR system (Roche, Rotkreuz, Switzerland). ORF $1 a b$ was amplified from cDNA and cloned into MS2-nCoV-ORF1ab and used as the plasmid standard after its identity was confirmed by sequencing. A standard curve was generated by determination of 
copy numbers from serially dilutions (103-109 copies) of plasmid. The following primers used for quantitative PCR were ORFlab-F: $5^{\prime}$-AGAAGATTGGTTAGAT GATGATAGT- $3^{\prime}$, ORF1ab-R: 5'-TTCCATCTCTAATTGAGGTTGAACC- ${ }^{\prime}$, and probe 5'-FAM-TCCTCACTGCCGTCTTGTTGACCA-BHQ1-3'. In all, $72 \mathrm{~h}$ later, the cytopathic effect changes of the rest replicate were observed by microscope.

The $\mathrm{Ct}$ value was changed to virus copy number $\left(10^{y}\right)$ by formula $y=(\mathrm{Ct}-$ 35.461)/-3.4546 with Microsoft Excel 2016. The virus copy number in percent of different concentration inhibitors is divided by that of negative control to get percentage inhibition or percentage relative RNA copies with Microsoft Excel 2016. The inhibition curve was plotted by fitting $\log$ (inhibitor) vs. response (three parameters) mode with GraphPad Prism 8.0. The $\mathrm{EC}_{50}$ was also calculated in the table of results by GraphPad Prism 8.0. The column graph of relative RNA copies in percent of inhibitors and unpaired $t$ test between two columns were performed by GraphPad Prism 8.0.

Plaque-reduction assays. In all, $2 \times 10^{5}$ Vero cells were seeded in a 24-well plate and cultured overnight in 24 -well plate. The cells were infected by $200 \mu \mathrm{L}$ SARS$\mathrm{CoV}-2$ (100 PFU) for $2 \mathrm{~h}$. The medium was then removed, and fresh medium (DMEM contained 2\% FBS and 1.2\% Avicell) containing appropriate concentrations of inhibitors was added to the cells. The cells were incubated for $72 \mathrm{~h}$ at $37^{\circ} \mathrm{C}$ with $5 \% \mathrm{CO}_{2}$. The overlay was discarded. The cells were fixed for $30 \mathrm{~min}$ with $4 \%$ polyoxymethylene (Solarbio, P1110) and stained with crystal violet working solution for $15 \mathrm{~min}$.

Statistical analysis and reproducibility. The $p$ values described in this study were calculated by unpaired $t$ test using GraphPad Prism 8.0. Figures $2 \mathrm{c}-\mathrm{f}$ and Supplementary Fig. 5a-e have been repeated twice and similar results were observed.

Reporting summary. Further information on research design is available in the Nature Research Reporting Summary linked to this article.

\section{Data availability}

Figures 1a, b, d, f and 2a, b; Supplementary Figs. 2 and 4 have associated raw data in this paper. Supplementary files are available from the corresponding authors upon request. Atomic coordinates and structure factors have been deposited in the Protein Data Bank under accession codes PDB 7BRO, PDB 7BRP, PDB 7BRR, PDB 7C6U, and PDB 7C6S. Source data are provided with this paper.

Received: 23 May 2020; Accepted: 22 July 2020;

Published online: 04 September 2020

\section{References}

1. Wang, C., Horby, P. W., Hayden, F. G. \& Gao, G. F. A novel coronavirus outbreak of global health concern. Lancet 395, 470-473 (2020).

2. Tan, W. et al. A novel coronavirus genome identified in a cluster of pneumonia cases - Wuhan, China 2019-2020. China CDC Weekly 2, 61-62 (2020).

3. Li, Q. et al. Early transmission dynamics in wuhan, china, of novel coronavirus-infected pneumonia. New Engl. J. Med. 382, 1199-1207 (2020).

4. Zhou, P. et al. A pneumonia outbreak associated with a new coronavirus of probable bat origin. Nature 579, 270-273 (2020).

5. Zhu, N. et al. A Novel Coronavirus from patients with pneumonia in China, 2019. New Engl. J. Med. 382, 727-733 (2020).

6. Phan, L. T. et al. Importation and human-to-human transmission of a novel coronavirus in Vietnam. New Engl. J. Med. 382, 872-874 (2020).

7. Holshue, M. L. et al. First Case of 2019 Novel coronavirus in the United States. New Engl. J. Med. 382, 929-936 (2020).

8. WHO. WHO Director-General's opening remarks at the media briefing on COVID-19 - 11 March 2020, https://www.who.int/dg/speeches/detail/whodirector-general-s-opening-remarks-at-the-media-briefing-on-covid-19-11march-2020 (2020)

9. WHO. World Health Organization: Coronavirus disease (COVID-2019) situation reports, https://www.who.int/emergencies/diseases/novelcoronavirus-2019/situation-reports (2020).

10. Jiang, S. et al. A distinct name is needed for the new coronavirus. Lancet 395 , 949 (2020).

11. Coronaviridae Study Group of the International Committee on Taxonomy of Viruses. The species Severe acute respiratory syndrome-related coronavirus: classifying 2019-nCoV and naming it SARS-CoV-2. Nat. Microbiol. 5, 536-544 (2020).

12. Lu, R. et al. Genomic characterisation and epidemiology of 2019 novel coronavirus: implications for virus origins and receptor binding. Lancet 395, 565-574 (2020).
13. Guan, W.-j et al. Clinical characteristics of coronavirus disease 2019 in China. New Engl. J. Med. 382, 1708-1720 (2020).

14. Zhou, F. et al. Clinical course and risk factors for mortality of adult inpatients with COVID-19 in Wuhan, China: a retrospective cohort study. Lancet 395, 1054-1062 (2020)

15. Walls, A. C. et al. Structure, function, and antigenicity of the SARS-CoV-2 spike glycoprotein. Cell 181, 281-292.e6 (2020).

16. Wrapp, D. et al. Cryo-EM structure of the 2019-nCoV spike in the prefusion conformation. Science 367, 1260-1263 (2020)

17. Yan, R. et al. Structural basis for the recognition of SARS-CoV-2 by full-length human ACE2. Science 367, 1444-1448 (2020).

18. Wang, Q. et al. Structural and functional basis of SARS-CoV-2 entry by using human ACE2. Cell 181, 894-904.e9 (2020).

19. Dong, L., Hu, S. \& Gao, J. Discovering drugs to treat coronavirus disease 2019 (COVID-19). Drug Discov. Ther. 14, 58-60 (2020).

20. Wang, M. et al. Remdesivir and chloroquine effectively inhibit the recently emerged novel coronavirus (2019-nCoV) in vitro. Cell Res. 30, 269-271 (2020).

21. Lu, H. Drug treatment options for the 2019-new coronavirus (2019-nCoV). Biosci. Trends 14, 69-71 (2020).

22. Ni, L., Zhou, L., Zhou, M., Zhao, J. \& Wang, D. W. Combination of western medicine and Chinese traditional patent medicine in treating a family case of COVID-19. Front. Med. 14, 210-214 (2020).

23. Agbowuro, A. A., Huston, W. M., Gamble, A. B. \& Tyndall, J. D. A. Proteases and protease inhibitors in infectious diseases. Med. Res. Rev. 38, 1295-1331 (2018).

24. Cao, B. et al. A trial of lopinavir-ritonavir in adults hospitalized with severe Covid-19. New Engl. J. Med. 382, 1787-1799 (2020).

25. Xue, X. et al. Production of authentic SARS-CoV Mpro with enhanced activity: application as a novel tag-cleavage endopeptidase for protein overproduction. J. Mol. Biol. 366, 965-975 (2007).

26. Jin, Z. et al. Structure of Mpro from COVID-19 virus and discovery of its inhibitors. Nature 582, 289-293 (2020).

27. Prongay, A. J. et al. Discovery of the HCV NS3/4A protease inhibitor (1R,5S) $\mathrm{N}$-[3-amino-1-(cyclobutylmethyl)-2,3-dioxopropyl]-3- [2(S)-[[[(1,1dimethylethyl)amino]carbonyl]amino]-3,3-dimethyl-1-oxobutyl]- 6,6dimethyl-3-azabicyclo[3.1.0] hexan-2(S)-carboxamide (Sch 503034) II. Key steps in structure-based optimization. J. Med. Chem. 50, 2310-2318 (2007).

28. Malcolm, B. A. et al. SCH 503034, a mechanism-based inhibitor of hepatitis C virus NS3 protease, suppresses polyprotein maturation and enhances the antiviral activity of alpha interferon in replicon cells. Antimicrob. Agents Chemother. 50, 1013-1020 (2006).

29. Kim, Y. et al. Broad-spectrum antivirals against $3 \mathrm{C}$ or $3 \mathrm{C}$-like proteases of picornaviruses, noroviruses, and coronaviruses. J. Virol. 86, 11754-11762 (2012).

30. Pedersen, N. C. et al. Efficacy of a 3C-like protease inhibitor in treating various forms of acquired feline infectious peritonitis. J. Feline Med. Surg. 20, 378-392 (2018).

31. Zhang, L. et al. Crystal structure of SARS-CoV-2 main protease provides a basis for design of improved a-ketoamide inhibitors. Science 368, 409-412 (2020).

32. Dai, W. et al. Structure-based design of antiviral drug candidates targeting the SARS-CoV-2 main protease. Science 368, 1331-1335 (2020).

33. Lin, C., Kwong, A. D. \& Perni, R. B. Discovery and development of VX-950, a novel, covalent, and reversible inhibitor of hepatitis $\mathrm{C}$ virus NS3.4A serine protease. Infect. Disord. Drug Targets 6, 3-16 (2006).

34. Cummings, M. D. et al. Induced-fit binding of the macrocyclic noncovalent inhibitor TMC435 to its HCV NS3/NS4A protease target. Angew. Chem. Int. Ed. 49, 1652-1655 (2010).

35. Soumana, D. I., Ali, A. \& Schiffer, C. A. Structural analysis of asunaprevir resistance in HCV NS3/4A protease. ACS Chem. Biol. 9, 2485-2490 (2014).

36. Romano, K. P. et al. The molecular basis of drug resistance against hepatitis $\mathrm{C}$ virus NS3/4A protease inhibitors. PLoS Pathog. 8, e1002832 (2012).

37. Pedersen, N. C. et al. Efficacy of a 3C-like protease inhibitor in treating various forms of acquired feline infectious peritonitis. J. Feline Med. Surg. 20, 378-392 (2017).

38. Kim, Y. et al. Reversal of the progression of fatal coronavirus infection in cats by a broad-spectrum coronavirus protease inhibitor. PLoS Pathog. 12 , e1005531 (2016).

39. Yang, H. et al. Design of wide-spectrum inhibitors targeting coronavirus main proteases. PLoS Biol. 3, e324 (2005).

40. Yang, $H$. et al. The crystal structures of severe acute respiratory syndrome virus main protease and its complex with an inhibitor. Proc. Natl Acad. Sci. USA 100, 13190-13195 (2003).

41. Otwinowski, Z. \& Minor, W. Processing of X-ray diffraction data collected in oscillation mode. Methods Enzymol. 276, 307-326 (1997).

42. Read, R. J. Pushing the boundaries of molecular replacement with maximum likelihood. Acta Crystallogr. D Biol. Crystallogr. 57, 1373-1382 (2001). 
43. Emsley, P. \& Cowtan, K. Coot: model-building tools for molecular graphics. Acta Crystallogr. D Biol. Crystallogr. 60, 2126-2132 (2004).

44. Adams, P. D. et al. PHENIX: a comprehensive Python-based system for macromolecular structure solution. Acta Crystallogr. D Biol. Crystallogr. 66, 213-221 (2010).

45. Williams, C. J. et al. MolProbity: more and better reference data for improved all-atom structure validation. Protein Sci. 27, 293-315 (2018).

\section{Acknowledgements}

We thank the staff of BL17U beamlines at Shanghai Synchrotron Radiation Facility. We also thank Mr. Yi Han at the Institute of Biophysics Core-Facility for the support during in-house data collection. We also thank Hanxing Zhang and Guoxia Liu from the Institute of Microbiology, Chinese Academy of Sciences for help in enzyme activity analysis. This work was supported by the Strategic Priority Research Program of CAS (XDB29010202), the National Key Research and Development Program of China (2016YFD0500300, 2016YFE0205800), the National Science and Technology Major Project (2018ZX10733403), and National Natural Science Foundation of China (NSFC) (81673358 and 21807109).

\section{Author contributions}

X.L., W.T., J.Q., and G.F.G. initiated and coordinated the project. L.F. designed the experiments and performed enzyme related test. C.Z., Y.W., H.Sun, and Y.F. expressed protein and grew the crystals. F.Ye and B.H. completed antiviral assays, P.N. quantified viral RNA by RT-PCR, F.Yu and Q.W., and J.Q. collected the diffraction data and determined the structures. L.F., H.Song, G.F.G., and Y.S. wrote the manuscript.

\section{Additional information}

Supplementary information is available for this paper at https://doi.org/10.1038/s41467020-18233-x.

Correspondence and requests for materials should be addressed to X.L., W.T., J.Q. or G.F.G.

Peer review information Nature Communications thanks Haitao Yang and the other, anonymous, reviewer(s) for their contribution to the peer review of this work.

Reprints and permission information is available at http://www.nature.com/reprints

Publisher's note Springer Nature remains neutral with regard to jurisdictional claims in published maps and institutional affiliations.

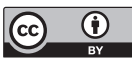

Open Access This article is licensed under a Creative Commons Attribution 4.0 International License, which permits use, sharing, adaptation, distribution and reproduction in any medium or format, as long as you give appropriate credit to the original author(s) and the source, provide a link to the Creative Commons license, and indicate if changes were made. The images or other third party material in this article are included in the article's Creative Commons license, unless indicated otherwise in a credit line to the material. If material is not included in the article's Creative Commons license and your intended use is not permitted by statutory regulation or exceeds the permitted use, you will need to obtain permission directly from the copyright holder. To view a copy of this license, visit http://creativecommons.org/ licenses/by/4.0/.

(c) The Author(s) 2020

\section{Competing interests}

The authors declare no competing interests. 